\section{Anti-inflammatory efficacy of a single posterior subtenon injection of triamcinolone acetonide versus prednisolone acetate $1 \%$ eyedrops after pars plana vitrectomy}

Letícia Paccola, ${ }^{1}$ Rodrigo Jorge, ${ }^{1}$ José C. Barbosa, ${ }^{2}$ Rogério A. Costa ${ }^{1,3}$ and Ingrid U. Scott ${ }^{4}$

${ }^{1}$ Department of Ophthalmology, School of Medicine of Ribeirão Preto, Ribeirão Preto, São Paulo, Brazil

${ }^{2}$ Exact Sciences Department, UNESP-Jaboticabal, Jaboticabal, São Paulo, Brazil

${ }^{3}$ Hospital de Olhos de Araraquara, Araraquara, São Paulo, Brazil

${ }^{4}$ Department of Ophthalmology and Visual Sciences, Penn State College of

Medicine, Hershey, Pennsylvania, USA

\begin{abstract}
.
Purpose: To compare the safety and anti-inflammatory efficacy of a single posterior subtenon injection of triamcinolone acetonide (TA) with prednisolone acetate $1 \%$ eyedrops after pars plana vitrectomy (PPV).

Methods: The study included 40 consecutive phakic eyes of 40 patients undergoing PPV for non-clearing vitreous haemorrhage with attached retina (verified by echography), epiretinal membrane or macular hole. At the end of the surgical procedure, eyes were randomized to receive either a single posterior subtenon injection of TA $(40 \mathrm{mg}$ in $1 \mathrm{ml})$ plus sham eyedrops (prednisolone acetate $1 \%$ vehicle) postoperatively (group TA), or a posterior subtenon sham injection $(1 \mathrm{ml}$ balanced salt solution) plus prednisolone acetate $1 \%$ eyedrops postoperatively (group ED).

Results: There was no difference in the severity of anterior chamber cell and flare between the two groups at any time-point during the study period $(p>0.05)$. Separate within-group analysis revealed a significant decrease in anterior chamber cell and flare from postoperative day 1 to postoperative days 7,14 and 28 in both groups $(p<0.05)$. There was no difference in pain, photophobia, conjunctival erythema, ciliary flush or chemosis scores between the two groups at any time-point during the study period $(p>0.05)$. Steroidinduced intraocular hypertension was not observed in either group.

Conclusions: A single posterior subtenon injection of TA can be as effective and safe as a 4-week regimen of prednisolone acetate $1 \%$ eyedrops in controlling intraocular inflammation after PPV.
\end{abstract}

Key words: drug delivery - inflammation - postoperative care - prednisolone - triamcinolone vitrectomy - vitreous

Acta Ophthalmol. Scand. 2007: 85: 603-608

(c) 2007 The Authors

Journal compilation @ 2007 Acta Ophthalmol Scand

doi: $10.1111 / j .1600-0420.2007 .00923 . x$

\section{Introduction}

Postoperative ocular inflammation is a local response that begins immediately after surgical trauma (Chalan et al. 2003). Corticosteroids have been used systemically, regionally and topically to reduce the ocular inflammatory response after various types of ophthalmic surgery (Flood et al. 1999; Fuller et al. 2002; Hoffman et al. 2003; Trinavarat et al. 2003; Fan et al. 2005; Roman Guindo et al. 2005), including pars plana vitrectomy (PPV) (Chalan et al. 2003; Yulek et al. 2006). Although steroid eyedrops are routinely used postoperatively to control ocular inflammation following PPV (Krohn 2003), topical therapy is associated with the well recognized problem of patient compliance (Winfield et al. 1990). In addition to topical therapy, intravitreal dexamethasone has been proposed recently as an adjunctive treatment to reduce postoperative inflammation after vitreoretinal surgery (Chalan et al. 2003).

Sub-Tenon's capsule injection of a depot corticosteroid is a currently established modality for the treatment of various inflammatory eye diseases, with good therapeutic response and 
ocular tolerance (Helm \& Holland 1995; Zamir et al. 2002). Its prolonged therapeutic effect has provided the ophthalmologist with an alternative approach for the control of intraocular inflammation (Lafranco et al. 1999; Okada et al. 2003). This rationale can be extrapolated to the surgical arena to modulate postoperative inflammation.

The objective of the current study was to compare the safety and antiinflammatory efficacy of a single posterior subtenon injection of triamcinolone acetonide (TA) with prednisolone acetate $1 \%$ eyedrops to control postoperative inflammation after PPV.

\section{Materials and Methods}

The study protocol adhered to the tenets of the Declaration of Helsinki and was approved by the local institutional review board. All participants gave written informed consent before entering the study. A total of 40 eyes of 40 patients were enrolled in this double-masked, randomized, controlled study.

\section{Study population}

Patients were included if they had a phakic eye scheduled to undergo PPV under peribulbar anaesthesia for:

(1) Non-clearing vitreous haemorrhage with attached retina (verified by echography);

(2) epiretinal membrane, or

(3) macular hole.

Exclusion criteria were:

(1) cataract sufficiently dense to require lensectomy at the time of PPV;

(2) anterior chamber flare or cells on preoperative evaluation;

(3) previous intraocular surgery;

(4) history of uveitis, glaucoma or ocular hypertension (intraocular pressure [IOP] > $22 \mathrm{mmHg}$ );

(5) use of any topical or systemic anti-inflammatory medication within 1 month prior to PPV, and

(6) severe systemic disease or any condition affecting follow-up.

All patients attending the Retina and Vitreous Section of the Department of Ophthalmology, School of Medicine of Ribeirão Preto, between July and December 2004, who met study eligibility criteria were invited to participate in the study. Of the 45 patients invited, five declined because of fear of ocular hypertension secondary to subtenon TA injection, a potential complication detailed in the informed consent.

\section{Treatment assignment and study masking}

All surgeries were performed by the same surgeon (RJ). Postoperative anterior segment biomicroscopy evaluations and IOP measurements were performed by the same retinal specialist (LP), who was unaware of patient treatment assignment. The data were analysed by RAC and JCB, who were also unaware of patient treatment assignment. Patients were instructed not to use any systemic anti-inflammatory drugs during the course of the study.

Patients were assigned to one of the two postoperative treatment regimens (designated 'ED' or 'TA') using a table of computer-generated random numbers. Group ED patients were administered a sham posterior subtenon injection of balanced salt solution (BSS) $(1 \mathrm{ml})$ at the conclusion of PPV, and were instructed to selfadminister prednisolone acetate $1 \%$ eyedrops (PredFort; Allergan Inc., São Paulo, SP, Brazil) into the operated eye, at one drop per dose, according to the following schedule: five times daily in week 1; three times daily in week 2; twice daily in week 3, and once daily in week 4. Group TA patients were treated with a single posterior subtenon injection of $40 \mathrm{mg} / 1 \mathrm{ml}$ triamcinolone acetonide (Ophthalmos, São Paulo, SP, Brazil) at the conclusion of the PPV and sham eyedrops (consisting of the Pred Forte vehicle) were prescribed according to the aforementioned schedule. Patients in both groups were instructed to self-administer ciprofloxacin $0.3 \%$ eyedrops (Ciprofloxacina; Allergan Inc.) into the operated eye four times daily.

\section{Surgical procedure}

Before surgery, all eyes were dilated with two drops of $10 \%$ phenylephrine eyedrops administered 5 mins apart and three drops of $1 \%$ tropicamide eyedrops administered 3 mins apart. Surgery was performed under peribulbar anaesthesia using $5 \mathrm{ml}$ $0.5 \%$ bupivacaine and $5 \mathrm{ml} 2 \%$ lidocaine. A fornix-based conjunctival peritomy was made both temporally and nasally. A standard 20-gauge, three-port PPV was performed using a DORC vitrectomy machine (DORC, Zuidland, The Netherlands). For macular pucker and macular hole surgeries, an microvitreoretinal blade (MVR) blade was used to peel the epiretinal membrane (ERM) and/or internal limiting membrane (ILM) and an Eckardt forceps (DORC) was used to remove the ERM and/or ILM. For macular hole surgery, indocyanine green was used to stain the ILM. Endolaser was performed in all non-clearing vitreous haemorrhage cases (diabetic retinopathy, $n=18$, and branch retinal vein occlusion, $n=3$ ). The conjunctival peritomies were closed at the end of surgery with 7.0 Vicryl $^{\circledR}$ sutures. In 14 cases $16 \%$ perfluoropropane was used as a vitreous substitute; BSS was used in 26 cases. For the posterior subtenon injections, we used a curved blunt cannula similar to that used by the Anecortave Acetate Clinical Study Group (2003). The cannula was affixed to a syringe and introduced through the PPV temporal conjunctival incision, between Vicryl ${ }^{\circledR}$ sutures, about $8 \mathrm{~mm}$ posterior to the limbus, and saline or triamcinolone acetonide was then injected.

\section{Outcome measures}

Efficacy outcomes were evaluated by a masked examiner who performed slitlamp biomicroscopy before pupil dilation at baseline and during all followup visits; the efficacy outcome variables were graded according to the system published by Solomon et al. (2001).

The primary efficacy outcome variables were anterior chamber cells and flare. Anterior chamber cells were graded on a scale of $0-4$, where $0=$ none (no cells), $1=$ mild $(1-5$ cells), $2=$ moderate $(6-15$ cells $), 3=$ severe $(16-$ 30 cells) and $4=$ very severe $(>30$ cells). Anterior chamber flare was also graded on a scale of $0-4$, where $0=$ none (no Tyndall effect), $1=$ mild (barely discernible Tyndall effect), 2 = moderate (moderately intense Tyndall beam in anterior chamber), $3=$ severe (severely intense Tyndall beam), and $4=$ very severe (very severely intense Tyndall beam with a white and milky appearance of the aqueous). 
Additional efficacy variables were conjunctival erythema, ciliary flush, chemosis and symptoms of ocular inflammation such as photophobia and pain. These variables were evaluated on a scale of $0-4$, with single grade increments, where $0=$ none and $4=$ very severe.

Safety variables monitored included adverse events, IOP and other biomicroscopic and ophthalmoscopic findings. Throughout the study, any signs or symptoms of adverse events were recorded, graded for severity, and assessed for their relationship to the study treatment. At each visit, IOP was measured by Goldmann applanation tonometry. Best corrected visual acuity (BCVA) in the study eye was measured using the Snellen VA chart. In addition, complete biomicroscopic and ophthalmoscopic examinations were conducted at baseline and at all follow-up visits. Patients were able to withdraw from the study at any time. Although investigators were permitted to remove any patient from the study if the investigator believed it was not in the patient's best interest to continue the study, no patient was removed.

\section{Data analysis}

To study the effect of each antiinflammatory treatment at the prespecified study follow-up intervals (postoperative days 1, 7, 14 and 28), analysis of variance (ANOVA) with a split-plot design was used, considering the group factor as the main effect (group TA and group ED), and the four postoperative follow-up intervals as the subplot factor. Tukey's test was used for multiple comparisons at the $5 \%$ level of significance $(\mathrm{p}<0.05)$.

\section{Results}

Each of the 40 patients enrolled was randomly assigned to one of the two treatment groups (20 per group). All patients in both groups completed the study. Demographic characteristics of the study population are summarized in Table 1. Patient age ranged from 49 to 78 years, with a mean \pm standard deviation (SD) of $63.1 \pm 6.5$ years. Women comprised $40 \%(16 / 40)$ of the patients, and men $60 \%(24 / 40)$. There was no significant difference between
Table 1. Patient demographics.

\begin{tabular}{lcc}
\hline Variables & $\begin{array}{c}\text { ED group* } \\
(n=20)\end{array}$ & $\begin{array}{c}\text { TA group } \dagger \\
(n=20)\end{array}$ \\
\hline $\begin{array}{l}\text { Age (years) } \\
\text { Mean } \pm \text { SD } \\
\text { Gender }\end{array}$ & $62.3 \pm 7.3$ & $61.9 \pm 7.9$ \\
$\quad \begin{array}{l}\text { Female } \\
\text { Male }\end{array}$ & $8(40 \%)$ & $8(40 \%)$ \\
$\begin{array}{l}\text { Race } \\
\text { Black }\end{array}$ & $12(60 \%)$ & $12(60 \%)$ \\
White & $8(40 \%)$ & $4(20 \%)$ \\
Asian & $10(50 \%)$ & $15(75 \%)$ \\
& $2(10 \%)$ & $1(5 \%)$ \\
\hline
\end{tabular}

* The ED group received a posterior subtenon sham injection ( $1 \mathrm{ml}$ balanced salt solution) plus prednisolone acetate $1 \%$ eyedrops postoperatively.

$\dagger$ The TA group received a posterior subtenon injection of triamcinolone acetonide (40 $\mathrm{mg}$ in $1 \mathrm{ml}$ ) plus sham eyedrops (prednisolone acetate $1 \%$ vehicle) postoperatively. $\mathrm{SD}=$ standard deviation.

treatment groups in age, gender, race or vitreoretinal disease. A total of 21 patients (TA group, $n=11$; ED group, $n=10$ ) had non-clearing vitreous haemorrhage; nine patients had idiopathic macular hole (TA group, $n=4$; ED group, $n=5$ ) and 10 patients had ERM (TA group, $n=5$; ED group, $n=5)$.

\section{Efficacy}

Anterior chamber cells and flare

No interaction between groups and periods was observed for anterior chamber cell $(F=1.08, \quad \mathrm{p}>0.05)$ and flare $(F=0.15, \mathrm{p}>0.05)$ scores using two-way Anova. There was no difference in anterior chamber cell and flare scores between the two groups at any follow-up interval during the study period (Figs 1 and 2, Table 2). Separate within-group analysis revealed a significant decrease in anterior chamber cell and flare scores from postoperative day 1 to postoperative days 7, 14 and 28 in both groups $(\mathrm{p}<0.05)$. There was also a significant decrease in anterior chamber cell scores from day 7 to day 14 , and from day 14 to day 28 in each group $(p<0.05)$. The same significant decrease from one visit to another occurred for anterior chamber flare scores, with the exception of visits on days 14 and 28 in the TA group, where the difference in flare scores was not statistically different.

\section{Conjunctival erythema, ciliary flush, pain and photophobia}

No interaction between treatment groups and periods was observed for pain $(F=0.70, \mathrm{p}>0.05)$, photophobia $(F=1.12, \mathrm{p}>0.05)$, conjunctival erythema $(F=0.57, \mathrm{p}>0.05)$, ciliary flush $(F=0.46, \mathrm{p}>0.05)$, or chemosis $(F=0.48, \mathrm{p}>0.05)$ scores using two-way Anova. There was no difference in pain, photophobia, conjunctival erythema, ciliary flush or chemosis scores between the two groups at any

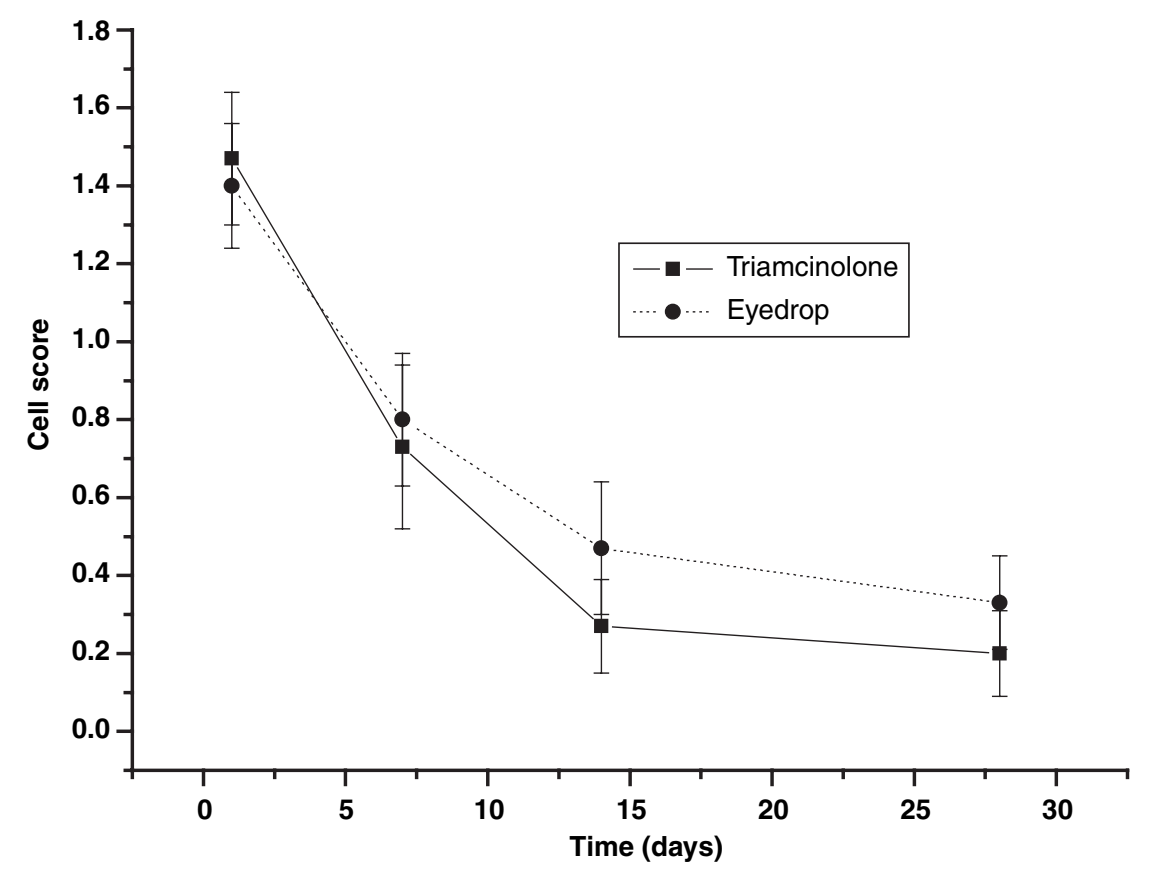

Fig. 1. Anterior chamber cell scores at 1, 7, 14 and 28 days after pars plana vitrectomy. 


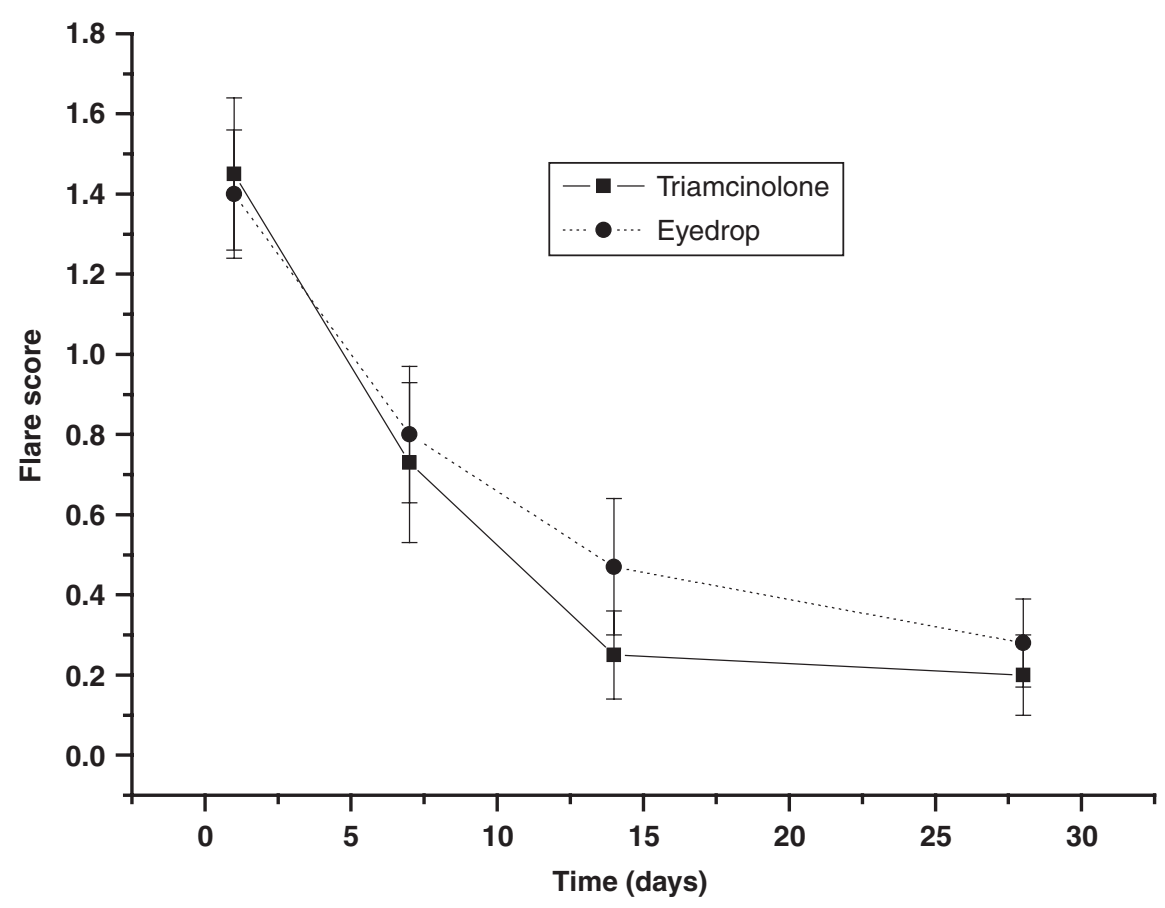

Fig. 2. Anterior chamber flare scores at 1, 7, 14 and 28 days after pars plana vitrectomy.

Table 2. Variables at each study visit (mean \pm standard error of the mean).

\begin{tabular}{lllllll}
\hline Variables & Group* & Day 1 & Day 7 & Day 14 & Day 28 & p \\
\hline Pain & TA & $1.40 \pm 0.13$ & $0.93 \pm 0.15$ & $0.33 \pm 0.13$ & $0.13 \pm 0.09$ & $<0.0001$ \\
& ED & $1.67 \pm 0.23$ & $1.13 \pm 0.22$ & $0.33 \pm 0.13$ & $0.07 \pm 0.07$ & $<0.0001$ \\
& p & 0.1641 & 0.2954 & 1.0000 & 0.7265 & \\
Photophobia & TA & $1.47 \pm 0.27$ & $0.47 \pm 0.17$ & $0.00 \pm 0.00$ & $0.07 \pm 0.07$ & $<0.0001$ \\
& ED & $1.30 \pm 0.15$ & $0.40 \pm 0.16$ & $0.13 \pm 0.09$ & $0.00 \pm 0.00$ & $<0.0001$ \\
& p & 0.123 & 0.7321 & 0.4940 & 0.7321 & \\
AC cell & TA & $1.47 \pm 0.17$ & $0.73 \pm 0.21$ & $0.27 \pm 0.12$ & $0.20 \pm 0.11$ & $<0.0001$ \\
& ED & $1.40 \pm 0.16$ & $0.80 \pm 0.17$ & $0.47 \pm 0.17$ & $0.33 \pm 0.12$ & $<0.0001$ \\
& p & 0.6399 & 0.6399 & 0.2626 & 0.1138 & \\
AC flare & TA & $1.45 \pm 0.19$ & $0.73 \pm 0.20$ & $0.25 \pm 0.11$ & $0.20 \pm 0.10$ & $<0.0001$ \\
& ED & $1.40 \pm 0.16$ & $0.80 \pm 0.17$ & $0.47 \pm 0.17$ & $0.28 \pm 0.11$ & $<0.0001$ \\
& p & 0.7645 & 0.4165 & 0.2965 & 0.1041 & \\
Ciliary flush & TA & $1.11 \pm 0.22$ & $0.20 \pm 0.15$ & $0.00 \pm 00$ & $0.00 \pm 0.00$ & $<0.0001$ \\
& ED & $0.91 \pm 0.20$ & $0.28 \pm 0.10$ & $0.00 \pm 00$ & $0.00 \pm 0.00$ & $<0.0001$ \\
& p & 0.6250 & 0.4940 & 1.0000 & 1.0000 & \\
Conjunctival & TA & $2.47 \pm 0.22$ & $1.80 \pm 0.17$ & $1.33 \pm 0.13$ & $0.47 \pm 0.19$ & $<0.0001$ \\
hyperaemia & ED & $2.13 \pm 0.29$ & $1.73 \pm 0.18$ & $1.40 \pm 0.13$ & $0.40 \pm 0.19$ & $<0.0001$ \\
& p & 0.1367 & 0.7645 & 0.7645 & 0.7645 & \\
Chemosis & TA & $1.00 \pm 0.14$ & $0.23 \pm 0.17$ & $0.00 \pm 0.00$ & $0.00 \pm 0.00$ & $<0.0001$ \\
& ED & $1.07 \pm 0.15$ & $0.30 \pm 0.13$ & $0.00 \pm 0.00$ & $0.00 \pm 0.00$ & $<0.0001$ \\
& p & 0.6250 & 0.3293 & 1.0000 & 1.0000 & \\
IOP (mmHg) & TA & $27.27 \pm 1.47$ & $22.13 \pm 1.17$ & $19.67 \pm 0.86$ & $19.60 \pm 0.84$ & $<0.0001$ \\
& ED & $24.80 \pm 1.06$ & $21.40 \pm 1.34$ & $20.27 \pm 1.18$ & $20.20 \pm 0.93$ & 0.0006 \\
& p & 0.0510 & 0.5461 & 0.6213 & 0.6213 & \\
\hline
\end{tabular}

* The TA group received a posterior subtenon injection of triamcinolone acetonide $(40 \mathrm{mg}$ in $1 \mathrm{ml}$ ) plus sham eyedrops (prednisolone acetate $1 \%$ vehicle) postoperatively. The ED group received a posterior subtenon sham injection $(1 \mathrm{ml}$ balanced salt solution) plus prednisolone acetate $1 \%$ eyedrops postoperatively.

$\mathrm{AC}=$ anterior chamber; $\mathrm{IOP}=$ intraocular pressure.

follow-up interval during the study period (Table 2). Separate withingroup analysis revealed a significant decrease in all the scores for these var- and conjunctival hyperaemia scores from day 7 to day 14, and from day 14 to day 28 in both groups $(\mathrm{p}<0.05)$. There was also a significant reduction in chemosis and ciliary flush scores from day 7 to day 14 in both groups and, at day 14 , these clinical features were absent in both groups. There was a significant reduction in pain scores from day 7 to day 14 , at which time scores for this variable were very low.

\section{Safety}

\section{Intraocular pressure}

No interaction between groups and follow-up intervals was observed for IOP values using two-way ANOvA $(F=1.44, \mathrm{p}>0.05)$. The mean IOP values for the two groups are displayed in Table 2. The between-group difference was not statistically significant at any postoperative visit $(\mathrm{p}>$ 0.05) (Fig. 3).

\section{Biomicroscopy and ophthalmoscopy}

No complications (such as infection, inadvertent injection into the choroidal or retinal circulation, perforation of the globe and occlusion of the central retinal artery) were observed in either group.

\section{Discussion}

Our results demonstrate no significant difference between a single posterior subtenon injection of TA $(40 \mathrm{mg} / 1 \mathrm{ml})$ and a 4-week regimen of prednisolone acetate $1 \%$ eyedrops in controlling the signs and symptoms of ocular inflammation after PPV. This is consistent with findings reported by Paganelli et al. (2004) for postoperative inflammation after cataract surgery. Chalan et al. (2003) reported that the use of intravitreal dexamethasone $(400 \mu \mathrm{g} / 0.1 \mathrm{ml})$ was associated with a significant reduction in flare intensity after PPV for proliferative diabetic retinopathy compared with prednisolone eyedrops.

The use of depot steroids, such as a posterior subtenon injection of TA, has many theoretical advantages over eyedrops in controlling postoperative inflammation. Depot steroids do not depend on patient compliance, which is a very important consideration, especially in developing nations (Paganelli et al. 2004). In addition, the 


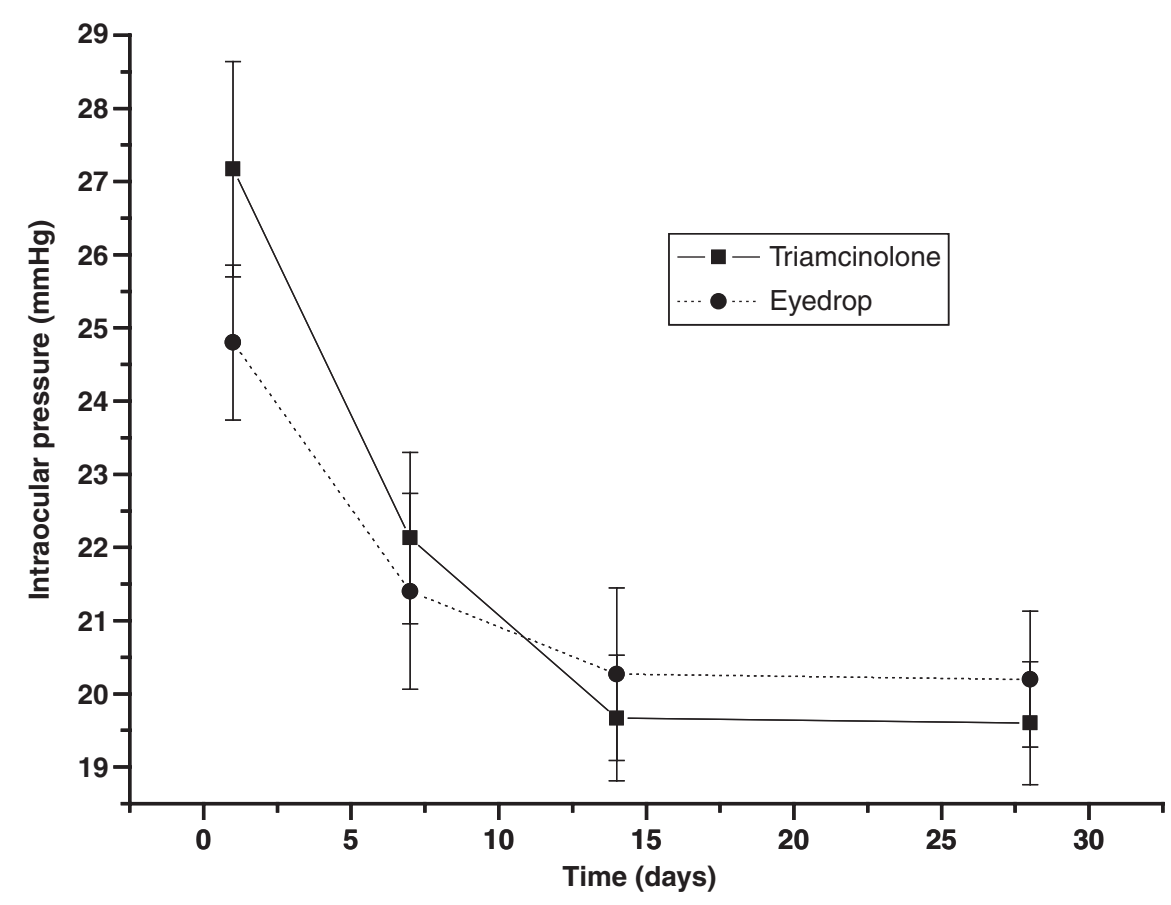

Fig. 3. Intraocular pressure at 1, 7, 14 and 28 days after pars plana vitrectomy.

ability of TA to treat macular oedema related to diabetic retinopathy (Bakri \& Kaiser 2005) and retinal vein occlusion (Lee \& Shah 2005) suggests that TA could be used to treat these disorders along with postoperative inflammation, particularly when using a 56 degree cannula that delivers the drug very close to the macular region (Anecortave Acetate Clinical Study Group 2003).

The current study demonstrated that a single posterior subtenon injection of TA was as safe as prednisolone acetate $1 \%$ eyedrops throughout the 4-week follow-up period. There were no significant differences between the two treatment groups in the frequency of adverse events. To our knowledge, and according to a computerized search of Medline, there is no published report of uncontrolled glaucoma after PPV with intraoperative or immediately postoperative administration of subtenon TA. Nevertheless, our study did not exclude a potential rise in IOP at more than 4 weeks postoperatively (Bonini-Filho et al. 2005).

Potential complications of posterior subtenon injection of corticosteroids include inadvertent injection into the choroidal or retinal circulation (Morgan et al. 1988), perforation of the globe (Ellis 1978), and occlusion of the central retinal artery (Ellis 1978). These complications are relatively rare and were not observed in the current study, which included eyes anaesthetized with peribulbar anaesthesia, which allows for complete control during subtenon injection of the steroid.

In conclusion, the current study indicates that a single posterior subtenon injection of TA is potentially as effective and safe as a 4-week regimen of prednisolone acetate $1 \%$ eyedrops in controlling intraocular inflammation after PPV.

\section{References}

Anecortave Acetate Clinical Study Group (2003): Anecortave acetate as monotherapy for treatment of subfoveal neovascularization in age-related macular degeneration: 12-month clinical outcomes. Ophthalmology 110: 2372-2385.

Bakri SJ \& Kaiser PK (2005): Posterior subtenon triamcinolone acetonide for refractory diabetic macular oedema. Am J Ophthalmol 139: 290-294.

Bonini-Filho MA, Jorge R, Barbosa JC, Calucci D, Cardillo JA \& Costa RA (2005): Intravitreal injection versus sub-Tenon's infusion of triamcinolone acetonide for refractory diabetic macular oedema: a randomized clinical trial. Invest Ophthalmol Vis Sci 46: 3845-3849.

Chalan KV, Malkani S \& Shah AV (2003): Intravitreal dexamethasone effectively reduces postoperative inflammation after vitreoretinal surgery. Ophthalmic Surg Lasers Imaging 34: 188-192.

Ellis PP (1978): Occlusion of the central retinal artery after retrobulbar corticosteroid injection. Am J Ophthalmol 85: 352-356.

Fan DS, Lam DS, Ng JS, Yu CB, Wong CU \& Cheung AY (2005): Ocular hypertensive and anti-inflammatory responses to different dosages of topical dexamethasone in children: a randomized trial. Clin Exp Ophthalmol 33: 252-258.

Flood TR, McManners J, el-Attar A \& Moos KF (1999): Randomized prospective study of the influence of steroids on postoperative eye-opening after exploration of the orbital floor. Br J Oral Maxillofac Surg 37: 312-315.

Fuller JR, Bevin TH, Molteno AC, Vote BJ \& Herbison P (2002): Anti-inflammatory fibrosis suppression in threatened trabeculectomy bleb failure produces good longterm control of intraocular pressure without risk of sight-threatening complications. Br J Ophthalmol 86: 1352-1354.

Helm CJ \& Holland GN (1995): The effects of posterior subtenon injection of triamcinolone acetonide in patients with intermediate uveitis. Am J Ophthalmol 120: 55 64.

Hoffman RS, Fine IH \& Packer M (2003): Incidence and outcomes of LASIK with diffuse lamellar keratitis treated with topical and oral corticosteroids. J Cataract Refract Surg 29: 451-456.

Krohn J (2003): Topical medication interferes with face-down positioning after macular hole surgery. Acta Ophthalmol Scand 81: 226-229.

Lafranco Dafflon M, Tran VT, Guex-Crosier Y \& Herbort Carl P (1999): Posterior subTenon's steroid injections for the treatment of posterior ocular inflammation: indications, efficacy and side-effects. Graefes Arch Clin Exp Ophthalmol 237: 289-295.

Lee H \& Shah GK (2005): Intravitreal triamcinolone as primary treatment of cystoid macular oedema secondary to branch retinal vein occlusion. Retina 25: 551-555.

Morgan CM, Schatz H, Vine AK et al. (1988): Ocular complications associated with retrobulbar injections. Ophthalmology 95: 660-665.

Okada AA, Wakabayashi T, Morimura Y et al. (2003): Trans-Tenon's retrobulbar triamcinolone infusion for the treatment of uveitis. Br J Ophthalmol 87: 968-971.

Paganelli F, Cardillo JA, Melo LA Jr et al. (2004): A single intraoperative sub-Tenon's capsule triamcinolone acetonide injection for the treatment of post-cataract surgery inflammation. Ophthalmology 111: 21022108.

Roman Guindo JM, Teus Guezala MA, Sanchez Pina JM et al. (2005): Evaluation of the efficacy of longterm topical steroid 
treatment to prevent regression after hyperopic LASIK. Arch Soc Esp Oftalmol 80 13-18.

Solomon KD, Cheetham JK, DeGryse R et al. (2001): Topical ketorolac trimethamine $0.5 \%$ ophthalmic solution in ocular inflammation after cataract surgery. Ophthalmology 108: 331-337.

Trinavarat A, Atchaneeyasakul LO, Surachatkumtonekul $\mathrm{T} \&$ Kosrirukvongs $\mathrm{P}$ (2003): Comparison of topical prednisolone acetate, ketorolac tromethamine and fluorometholone acetate in reducing inflammation after phacoemulsification. J Med Assoc Thai 86: 143-150.
Winfield AJ, Jessiman D, Williams A \& Esakowitz L (1990): A study of the causes of non-compliance by patients prescribed eyedrops. $\mathrm{Br} \mathrm{J}$ Ophthalmol 74: 477-480.

Yulek F, Ozdek S, Gurelik G \& Hasanreisoglu B (2006): Effect of topical steroids on corneal epithelial healing after vitreoretinal surgery. Acta Ophthalmol Scand 84: 319322.

Zamir E, Read RW, Smith RE et al. (2002): A prospective evaluation of subconjunctival injection of triamcinolone acetonide for resistant anterior scleritis. Ophthalmology 109: 798-807.
Received on September 24th, 2006.

Accepted on February 11th, 2007.

Correspondence:

Professor Dr Rodrigo Jorge

Docente e Chefe do Setor de Retina e Vítreo Hospital das Clínicas da Faculdade de Medicina de Ribeirão Preto

Avenida Bandeirantes 3900

Ribeirão Preto-SP 14049-900

Brazil

Tel: + 551636022423

Fax: + 551636022860

Email: rjorge@fmrp.usp.br 